\title{
Correlation Between the Extension of the Maxillary Sinus Floor and Malocclusion in Adolescent Patients Using a Cone-beam Computed Tomography
}

Min Xu

Anhui Medical University

Xiaoxiao Zhang

Anhui Medical University

Jiacai He

Anhui Medical University

Xinxing Guo

Jinan Stomatological Hospital

Yuanyuan Sang

Anhui Medical University

Zheng Zhang

Anhui Medical University

Yuanyin Wang

Anhui Medical University

Wenhua Xu

Anhui Medical University

Jianguang Xu ( $\nabla$ xujianguang@ahmu.edu.cn )

Anhui Medical University https://orcid.org/0000-0002-0888-0482

Research article

Keywords: malocclusion, maxillary sinus, cone beam computed tomography, adolescents

Posted Date: September 17th, 2020

DOI: https://doi.org/10.21203/rs.3.rs-66905/v1

License: (c) This work is licensed under a Creative Commons Attribution 4.0 International License. Read Full License 


\section{Abstract}

Background: The correlation between extension of the maxillary sinus floor and vertical facial skeletal patterns is important for designing orthodontic treatment plans. We correlated the extension of the maxillary sinus (MS) floor with different facial skeletal malocclusion in adolescent patients aged 10-19 years old using a cone-beam computed tomography.

Methods: The relationship between the root tips of upper posterior teeth and the sinus floor was typed and scored (0-4) using cone-beam computed tomography (CBCT) images. Scores of each tooth and each patient were formulated. The cephalometric radiographs were analyzed with Dolphin software to diagnose patients' facial skeletal types into three groups according to Frankfort mandibular plane angle (FMA) as high-angle, average-angle and low-angle groups and ANB angle as Class I, Class II and Class III groups separately. The influences caused by age, sex, and facial skeletal malocclusion on the tooth and patient score were analyzed.

Results: In high-angle group, the first molar (FM) score was significantly higher than that in the average-angle and low-angle groups ( $P=$ 0.018). Age has a positive effect on the patient score and some of the tooth scores, such as the second premolar (SPM) score, FM score, and the second molar (SM) score, and in the skeletal facial malocclusion. With increasing age, SM score increased along with FMA angles. No significant difference was found in the distribution of patient and tooth scores by ANB angles.

Conclusion: The relationship between the maxillary posterior roots and the sinus floor is correlated with facial skeletal malocclusion in 10to 19-year-old adolescents. More first molar root tips were inside the sinus in the high-angle group compared with the average-angle and low-angle skeletal patterns. With advancing age, more second molar root tips were more close to contact the sinus floor in the high-angle group. Consideration of the root-sinus position of the posterior maxillary area in different skeletal malocclusion before establishing an orthodontic treatment plan is recommended.

\section{Background}

The maxillary sinus (MS) is the largest paranasal sinus and the first to develop, and it grows proportionally with facial bones ${ }^{1,2}$. The inferior wall of MS, or sinus floor, supports the roots of the maxillary dentition and continues with the alveolar process. The relationship between the root apex and the MS floor (root-sinus relationship), and the correlation between the root-sinus position and facial skeletal malocclusion are less considered when planning orthodontic treatment. However, tooth movement through the MS, is regarded as one of the most difficult tasks in orthodontics ${ }^{3}$. Except the side effects like root resorption and pulp vitality, movement of the tooth against the cortical bone is another challenging problem to address. Hence, the root-sinus relationship is relevant in orthodontic clinic.

The World Health Organization (WHO) defines adolescents to those between 10 and 19 years of age ${ }^{4}$. During adolescence, the growth and development of the MS are associated with the posterior maxillary teeth, which can be susceptible to malocclusion ${ }^{5,6}$. There is a close relationship between the upper maxillary teeth and the sinus floor ${ }^{7-9}$. However, few studies have addressed the correlation between the extension of the MS floor and skeletal malocclusion in adolescents.

Assessing the anatomical position of posterior maxillary tooth roots to the MS floor is essential when they are in close proximity. Conebeam computed tomographic (CBCT) imaging is indicated to provide detailed information at the structure of interest with relatively low radiation exposure ${ }^{10}$, which can also be used to analyze three-dimensional (3D) cephalometric images and create tissue reconstruction for further analysis. Our goal was to correlate the extension of the MS floor to malocclusion in adolescents and to provide recommendations for clinical orthodontic treatment.

\section{Methods}

\section{Subjects}

The cephalometric radiographs and dental СВCT images used in this study were selected from the СВCT database at radiology department at the Stomatological Hospital of $* \star \star$. This study was approved by an institutional review board for its retrospective property. Patients with pre-obtained CBCT images for orthodontic needs within the recent 2 years were included and a total image data of 178 patients were finally analyzed in this study (Figure 1).

\section{Inclusion Criteria}


1. Patients between 10 to 19 years old.

2. No loss of maxillary premolar or molar teeth.

3. No dental defects or root damage.

4. Completeness and continuity of the MS floor.

\section{Exclusion Criteria}

1. Images with many blurs or artifacts.

2. Craniofacial deformities, genetic syndromes, or other systemic diseases.

3. Previous orthodontic treatment.

4. Presence of periapical or periodontal diseases or history of endodontics treatment.

5. Presence of sinus floor augmentation, injuries, or trauma in the maxillofacial region.

6. Not fully developed root apex of maxillary posterior teeth.

\section{Radiographic Evaluations}

Cephalometric data were saved in JPG format, and CBCT data were saved in DICOM format. Evaluations of facial skeletal malocclusion and root-sinus relationship were processed using 3D software (Ver. 11.7 Premium; Dolphin Imaging, Chatsworth, CA, USA).

The following anatomic landmarks were identified on lateral cephalometric radiographs to determine the classification of skeletal malocclusion: Sella, Nasion, Porion, Orbitale, point A, point B, Pognion, Menton, and Gonion. ANB is defined as the angle between the NA (Nasion-A point) line and NB (Nasion-A point) line. Based on the range of the ANB angle ${ }^{11,12}$, patients were divided into three malocclusion groups: $0^{\circ}<$ ANB $<4^{\circ}$ were classified into skeletal Class I malocclusion, ANB $\geq 4^{\circ}$ were classified as skeletal Class II malocclusion, and ANB $<0^{\circ}$ were classified as skeletal Class III malocclusion. The line connecting Menton and Gonion was identified as the mandibular plane, and the angle formed by the mandibular plane and Frankfort horizontal plane was the Frankfort mandibular plane angle (FMA). A normal value was considered to be $25^{\circ} \pm 3^{\circ 13}$. Patients were divided into average-angle $\left(22^{\circ} \leq \mathrm{FMA} \leq 28^{\circ}\right)$, low-angle $\left(\mathrm{FMA}<22^{\circ}\right)$, and high-angle $(\mathrm{FMA}$ $>28^{\circ}$ ) skeletal malocclusion types.

The root tip was precisely located with CBCT images in coronal, sagittal, and transverse sections and the root-sinus relationship was verified according to Jung ${ }^{14}$. The vertical spatiality between the MS floor and molar roots could be classified into four types: 0 ) no contact between the root and the cortical borders of the MS; 1) slight contact between the root and the cortical borders of the MS; 2 ) a lateral protrusion of a root in the sinus cavity without the projection of its apex into the sinus; and 3) a projection of the root apex into the sinus cavity (Figure 2). The relationship between the root tips of the premolars as well as molars and the sinus floor was analyzed on CBCT scans and repeated after 30 days to assess the reliability. The left and right sides of each patient, each root tip of each premolar or molar, were categorized and regarded as independent. The examiner was blinded to the basic information of patients and all previous measurements.

Another examiner conducted all cephalometric measurements and repeated them after 30 days. The examiner was also blinded to the details of patients and previous evaluation results.

\section{Statistical analysis}

For each tooth, an average tooth score was calculated according to Formula 1 and recorded as FPM (the first premolar), SPM (the second premolar), FM (the first molar), and SM (the second molar) separately. For each patient, an average patient score was calculated using Formula 2.

Formula 1: Tooth score $=\frac{\left.\sum \text { (types of left and right roots }\right)}{\sum(\text { numbers of left and right roots })}$

Formula 2: Patient score $=\frac{\left.\sum \text { (types of all left and right roots of posterior teeth }\right)}{\left.\sum \text { (numbers of all left and right roots of posterior teeth }\right)}$ 
Results are presented in numbers (percentages), means, and standard deviations. All statistics were performed with IBM SPSS Statistics 23.0 software. A normality test was used to check the distribution of groups, and a consistency test was used to determine the test-retest reliability. For variables that were not normally distributed, differences were analyzed by the Kruskal-Wallis test. These included age, teeth per patient, roots per patient, tooth score, and patient score. Chi-square tests were used to analyze the differences between groups according to sex. Correlations between patient score, tooth score, age, and skeletal malocclusions were analyzed with the Spearman coefficient of correlation. The influence of skeletal malocclusion on tooth and patient scores was analyzed using a general linear regression model. $P<0.05$ was considered to be statistical significance.

\section{Results}

This research included 178 patients, consisting of 94 female patients and 84 male patients. The consistency test results for the reliability of cephalometric analysis and sinus-root type assessment between test-retest were $K=0.87(P<0.001)$ and $K=0.79(P<0.001)$, respectively.

The distributions of gender, age, teeth, and roots per patient, according to FMA angles and ANB angles, are given in Table 1. A comparison of gender, age, roots, and teeth per patient by FMA angles showed no significant differences between different sagittal skeletal pattern groups $(P>0.05)$. For ANB angles, a significant difference in teeth per patient was found between different coronal skeletal pattern groups $(P<0.05)$.

Table 1

Distribution of gender, age, roots per patient and teeth per patient by ANB angles and FMA angles

\begin{tabular}{|c|c|c|c|c|c|c|c|c|c|c|}
\hline Group & & $\begin{array}{l}\text { Total n } \\
(\%)\end{array}$ & Class I & Class II & Class III & $P$ & $\begin{array}{l}\text { Low- } \\
\text { angle }\end{array}$ & $\begin{array}{l}\text { Average- } \\
\text { angle }\end{array}$ & $\begin{array}{l}\text { High- } \\
\text { angle }\end{array}$ & $P$ \\
\hline \multirow[t]{2}{*}{ Gender } & Male & $84(0.47)$ & $\begin{array}{l}32 \\
(0.43)\end{array}$ & $\begin{array}{l}41 \\
(0.50)\end{array}$ & $\begin{array}{l}11 \\
(0.52)\end{array}$ & \multirow[t]{2}{*}{0.488} & $20(0.51)$ & $33(0.43)$ & $31(0.49)$ & \multirow[t]{2}{*}{0.594} \\
\hline & Female & $94(0.53)$ & $\begin{array}{l}43 \\
(0.57)\end{array}$ & $\begin{array}{l}41 \\
(0.50)\end{array}$ & $\begin{array}{l}10 \\
(0.48)\end{array}$ & & 19(0.49) & $43(0.57)$ & $32(0.51)$ & \\
\hline \multirow[t]{2}{*}{$\operatorname{Age}(y)$} & Mean & 14.29 & 14.12 & 14.39 & 14.58 & \multirow[t]{2}{*}{0.478} & 14.45 & 14.33 & 14.16 & \multirow[t]{2}{*}{0.888} \\
\hline & SD & 2.79 & 2.85 & 2.77 & 2.75 & & 2.78 & 2.95 & 2.63 & \\
\hline \multirow{2}{*}{$\begin{array}{l}\text { Roots per } \\
\text { patient }\end{array}$} & Mean & 14.34 & 13.84 & 14.74 & 14.68 & \multirow[t]{2}{*}{0.327} & 14.64 & 14.43 & 14.05 & \multirow[t]{2}{*}{0.399} \\
\hline & $\mathrm{SD}$ & 3.55 & 3.81 & 3.33 & 3.27 & & 3.74 & 3.31 & 3.75 & \\
\hline \multirow{2}{*}{$\begin{array}{l}\text { Teeth per } \\
\text { patient }\end{array}$} & Mean & 7.08 & 6.80 & 7.28 & 7.35 & \multirow[t]{2}{*}{$0.046^{\star}$} & 7.05 & 7.18 & 6.97 & \multirow[t]{2}{*}{0.947} \\
\hline & SD & 1.36 & 1.61 & 1.11 & 0.95 & & 1.33 & 1.13 & 1.62 & \\
\hline
\end{tabular}

The types of root-sinus relationship in the upper posterior area by ANB angles and FMA angles are presented in Table 2. A total of 2569 upper maxillary posterior roots (675 premolars and 582 molars) were assessed. These consisted of 791 type 0 roots, 421 type 1 root, 453 type 2 roots, and 904 type 3 roots. The most frequent root type was type 3 (35.19\%), and the second most frequent was type 0 (30.79\%). Grouped by ANB angles, 996 roots were categorized into Class I malocclusion, 1283 roots into Class II malocclusion, and 290 roots into Class III malocclusion. Grouped by FMA angles, 1108 roots were categorized into average-angle malocclusion, 566 roots into low-angle malocclusion, and 895 roots into high-angle malocclusion. 
Table 2

Frequencies (numbers and percentages) of root-sinus types by ANB angles and FMA angles

\begin{tabular}{|c|c|c|c|c|c|c|c|}
\hline & $\begin{array}{l}\text { Class I } \\
(n=72)\end{array}$ & $\begin{array}{l}\text { Class II } \\
(n=86)\end{array}$ & $\begin{array}{l}\text { Class III } \\
(n=20)\end{array}$ & Average-angle $(n=76)$ & $\begin{array}{l}\text { Low-angle } \\
(n=39)\end{array}$ & $\begin{array}{l}\text { High-angle } \\
(n=63)\end{array}$ & Total number of roots \\
\hline \multicolumn{8}{|c|}{ Root score $\quad \mathrm{n}(100 \%)$} \\
\hline 0 & $305(30.62)$ & 413(32.19) & 73(25.17) & $377(34.03)$ & 174(30.74) & $240(26.82)$ & 791(30.79) \\
\hline 1 & $160(16.06)$ & 197(15.35) & $64(22.07)$ & 177(15.97) & $94(16.61)$ & 150(16.76) & 421(16.39) \\
\hline 2 & 184(18.47) & 228(17.77) & $41(14.14)$ & $177(15.97)$ & $119(21.02)$ & $157(17.54)$ & $453(17.64)$ \\
\hline 3 & $347(34.84)$ & 445(34.68) & 112(38.62) & $377(34.03)$ & 179(31.63) & 348(38.88) & 904(35.19) \\
\hline Total & $996(100)$ & $1283(100)$ & 290(100) & $1108(100)$ & $566(100)$ & 895(100) & $2569(100)$ \\
\hline
\end{tabular}

The distribution of root-sinus types of each posterior teeth roots in different skeletal malocclusion groups is shown in Table 3 . The most frequent root-sinus type in all the roots of all the first premolars was type 0 regardless of malocclusion groups. Type 3 was the dominant relationship in the majority of roots of upper molars. No significant difference was found in the distribution of patient score and tooth score by ANB angles. Significant differences were found in the FPM and FM score by FMA angles (Table 4). The FPM in high-angle group was significantly lower than that in the average-angle and low-angle groups $(P=0.039)$. And FM in the high-angle group was significantly higher compared with that in the average-angle and low-angle groups $(P=0.018)$. 
Table 3

Numbers(percentages) of types of each root of each maxillary posterior tooth by ANB angles and FMA angles

\begin{tabular}{|c|c|c|c|c|c|c|c|c|c|}
\hline Roots & Root & Type & Class I & Class II & Class III & High-angle & $\begin{array}{l}\text { Average- } \\
\text { angle }\end{array}$ & Low-angle & Total \\
\hline \multicolumn{10}{|c|}{ first premolar $(n=350)$} \\
\hline \multirow[t]{4}{*}{1} & & 0 & $68(38.20)$ & $86(48.31)$ & $24(13.48)$ & 66(37.08) & $81(45.51)$ & $31(17.42)$ & $178(100)$ \\
\hline & & 1 & 8(34.78) & $10(43.48)$ & $5(21.74)$ & $10(43.48)$ & $6(26.09)$ & $7(30.43)$ & $23(100)$ \\
\hline & & 2 & $1(16.67)$ & $4(66.67)$ & $1(16.67)$ & $2(33.33)$ & $4(66.67)$ & $0(0)$ & $6(100)$ \\
\hline & & 3 & $2(66.67)$ & 1(33.33) & $0(0)$ & $0(0)$ & $3(100)$ & $0(0)$ & $3(100)$ \\
\hline \multirow[t]{8}{*}{2} & buccal & 0 & $44(41.90)$ & $56(53.33)$ & $5(4.76)$ & $30(28.57)$ & $47(44.76)$ & $28(26.67)$ & $105(100)$ \\
\hline & & 1 & $11(45.83)$ & $10(41.67)$ & $3(12.5)$ & $10(41.67)$ & $6(25)$ & 8(33.33) & $24(100)$ \\
\hline & & 2 & $3(37.5)$ & $4(50)$ & $1(12.5)$ & $1(12.5)$ & $4(50)$ & $3(37.5)$ & $8(100)$ \\
\hline & & 3 & $1(33.33)$ & 1(33.33) & $1(33.33)$ & $1(33.33)$ & $1(33.33)$ & 1(33.33) & $3(100)$ \\
\hline & palatal & 0 & $36(39.56)$ & $51(56.04)$ & $4(4.40)$ & $26(28.57)$ & $40(43.96)$ & $25(27.47)$ & $91(100)$ \\
\hline & & 1 & 18(51.43) & 13(37.14) & $4(11.43)$ & 12(34.29) & 12(34.29) & 11(31.43) & $35(100)$ \\
\hline & & 2 & $4(44.44)$ & $4(44.44)$ & 1(11.11) & $2(22.22)$ & $4(44.44)$ & $3(33.33)$ & $9(100)$ \\
\hline & & 3 & $1(20)$ & $3(60)$ & $1(20)$ & $2(40)$ & $2(40)$ & $1(20)$ & $5(100)$ \\
\hline \multicolumn{10}{|c|}{ second premolar $(n=325)$} \\
\hline \multirow[t]{4}{*}{1} & & 0 & $46(40)$ & $51(44.35)$ & 18(15.65) & $31(26.96)$ & $62(53.91)$ & $22(19.13)$ & $115(100)$ \\
\hline & & 1 & $31(39.74)$ & $40(51.28)$ & $7(8.97)$ & $36(46.15)$ & $27(34.62)$ & 15(19.23) & $78(100)$ \\
\hline & & 2 & $24(38.71)$ & $33(53.23)$ & $5(8.06)$ & $24(38.71)$ & $23(37.10)$ & $15(24.19)$ & $62(100)$ \\
\hline & & 3 & 18(33.96) & $27(50.94)$ & $8(15.09)$ & 18(33.96) & $23(43.40)$ & $12(22.64)$ & $53(100)$ \\
\hline \multirow[t]{8}{*}{2} & buccal & 0 & $0(0)$ & $7(100)$ & $0(0)$ & $2(28.57)$ & $3(42.86)$ & $2(28.57)$ & $7(100)$ \\
\hline & & 1 & $1(50)$ & $1(50)$ & $0(0)$ & $0(0)$ & $1(50)$ & $1(50)$ & $2(100)$ \\
\hline & & 2 & $1(25)$ & $2(50)$ & $1(25)$ & $1(25)$ & $1(25)$ & $2(50)$ & $4(100)$ \\
\hline & & 3 & $3(75)$ & $0(0)$ & $1(25)$ & $1(25)$ & $2(50)$ & $1(25)$ & $4(100)$ \\
\hline & palatal & 0 & $0(0)$ & $7(100)$ & $0(0)$ & $2(28.57)$ & $3(42.86)$ & $2(28.57)$ & $7(100)$ \\
\hline & & 1 & $0(0)$ & $0(0)$ & $0(0)$ & $0(0)$ & $0(0)$ & $0(0)$ & $0(100)$ \\
\hline & & 2 & $1(33.33)$ & $2(66.67)$ & $0(0)$ & $0(0)$ & 1(33.33) & $2(66.67)$ & $3(100)$ \\
\hline & & 3 & $4(57.14)$ & $1(14.29)$ & $2(28.57)$ & $2(28.57)$ & $3(42.86)$ & $2(28.57)$ & $7(100)$ \\
\hline \multicolumn{10}{|c|}{ first molar ( $n=355$ ) } \\
\hline \multirow[t]{8}{*}{3} & mesiobuccal & 0 & 12(31.78) & $23(60.53)$ & $3(7.89)$ & $9(23.68)$ & $20(52.63)$ & $9(23.68)$ & $38(100)$ \\
\hline & & 1 & $9(29.03)$ & $13(41.94)$ & $9(29.03)$ & $10(32.26)$ & $17(54.84)$ & $4(12.90)$ & $31(100)$ \\
\hline & & 2 & $29(40.28)$ & $36(50)$ & $7(9.72)$ & $22(30.56)$ & $34(47.22)$ & $16(22.22)$ & $72(100)$ \\
\hline & & 3 & $93(43.46)$ & $100(46.73)$ & $21(9.81)$ & $85(39.72)$ & 80(37.38) & $49(22.90)$ & $214(100)$ \\
\hline & distobuccal & 0 & 18(38.30) & $26(55.32)$ & $3(6.38)$ & $15(31.91)$ & $25(53.19)$ & $7(14.89)$ & $47(100)$ \\
\hline & & 1 & $22(42.31)$ & 19(36.54) & $11(21.15)$ & $11(21.15)$ & $27(51.92)$ & $14(26.92)$ & $52(100)$ \\
\hline & & 2 & $40(47.06)$ & $41(48.24)$ & $4(4.71)$ & $30(35.29)$ & $32(37.65)$ & $23(27.06)$ & $85(100)$ \\
\hline & & 3 & $63(36.84)$ & $86(50.29)$ & $22(12.87)$ & $70(40.94)$ & 67(39.18) & $34(19.88)$ & 171(100) \\
\hline
\end{tabular}




\begin{tabular}{|c|c|c|c|c|c|c|c|c|c|}
\hline Roots & Root & Type & Class I & Class II & Class III & High-angle & $\begin{array}{l}\text { Average- } \\
\text { angle }\end{array}$ & Low-angle & Total \\
\hline & \multirow[t]{4}{*}{ palatal } & 0 & $24(47.06)$ & $24(47.06)$ & $3(5.88)$ & 17(33.33) & $28(54.90)$ & $6(11.76)$ & $51(100)$ \\
\hline & & 1 & $7(28)$ & $12(48)$ & $6(24)$ & $2(8)$ & $17(68)$ & $6(24)$ & $25(100)$ \\
\hline & & 2 & $26(41.27)$ & $29(46.03)$ & $8(12.70)$ & $20(31.75)$ & $18(28.57)$ & $25(39.68)$ & $63(100)$ \\
\hline & & 3 & $86(39.81)$ & 107(49.54) & $23(10.65)$ & $87(40.28)$ & $88(40.74)$ & $41(18.98)$ & $216(100)$ \\
\hline \multicolumn{10}{|c|}{ second molar $(n=226)$} \\
\hline \multirow[t]{12}{*}{3} & mesiobuccal & 0 & $9(36.47)$ & $20(58.82)$ & $5(14.71)$ & $9(26.47)$ & $16(47.06)$ & $9(26.47)$ & $34(100)$ \\
\hline & & 1 & $14(35.90)$ & $20(51.28)$ & $5(12.82)$ & $11(28.21)$ & $20(51.28)$ & $8(20.51)$ & $39(100)$ \\
\hline & & 2 & $23(46)$ & $24(48)$ & $3(6)$ & $21(42)$ & $18(36)$ & $11(22)$ & $50(100)$ \\
\hline & & 3 & $35(33.98)$ & $55(53.40)$ & $13(12.62)$ & $39(37.86)$ & $46(44.66)$ & 18(17.48) & $103(100)$ \\
\hline & distobuccal & 0 & 14(31.82) & 26(59.09) & $4(9.09)$ & $9(20.45)$ & $20(45.45)$ & 15(34.09) & $44(100)$ \\
\hline & & 1 & $25(41.67)$ & $26(43.33)$ & $9(15)$ & $28(46.67)$ & 20(33.33) & $12(20)$ & $60(100)$ \\
\hline & & 2 & 17(36.96) & $28(60.87)$ & $1(2.17)$ & $17(36.96)$ & $20(43.48)$ & $9(19.57)$ & $46(100)$ \\
\hline & & 3 & $25(33.78)$ & $37(50)$ & $12(16.22)$ & $26(35.14)$ & $38(51.35)$ & $10(13.51)$ & $74(100)$ \\
\hline & palatal & 0 & $34(45.95)$ & $36(48.65)$ & $4(5.41)$ & $24(32.43)$ & $32(43.24)$ & $18(24.32)$ & $74(100)$ \\
\hline & & 1 & $14(26.92)$ & $33(63.46)$ & $5(9.62)$ & $20(38.46)$ & $24(46.15)$ & 8(15.38) & $52(100)$ \\
\hline & & 2 & 15(33.33) & $21(46.67)$ & $9(20)$ & $17(37.78)$ & $18(40)$ & $10(22.22)$ & $45(100)$ \\
\hline & & 3 & 16(31.37) & $27(52.94)$ & 8(15.69) & 17(33.33) & $24(47.06)$ & 10(19.61) & $51(100)$ \\
\hline TOTAL & & & 996(38.77) & $1283(49.94)$ & $290(11.29)$ & $895(34.84)$ & 1108(43.13) & $566(22.03)$ & $2569(100)$ \\
\hline
\end{tabular}

Table 4

Difference of patient score and tooth score in the different malocclusion groups

\begin{tabular}{|c|c|c|c|c|c|c|c|c|c|}
\hline & \multirow[t]{2}{*}{ Parameters } & \multicolumn{3}{|c|}{ Malocclusion groups } & \multirow[t]{2}{*}{$P$} & \multicolumn{3}{|c|}{ Malocclusion groups } & \multirow[t]{2}{*}{$P$} \\
\hline & & Class I & Class II & Class III & & Low-angle & Average-angle & High-angle & \\
\hline \multirow[t]{2}{*}{ Patient Score } & Mean & 1.53 & 1.60 & 1.53 & \multirow[t]{2}{*}{0.536} & 1.54 & 1.48 & 1.67 & \multirow[t]{2}{*}{0.093} \\
\hline & SD & 0.63 & 0.77 & 0.77 & & 0.66 & 0.76 & 0.67 & \\
\hline \multirow[t]{2}{*}{ FPM } & Mean & 0.29 & 0.27 & 0.33 & \multirow[t]{2}{*}{0.251} & 0.32 & 0.29 & 0.26 & \multirow[t]{2}{*}{$0.039^{x}$} \\
\hline & SD & 0.55 & 0.56 & 0.52 & & 0.47 & 0.63 & 0.48 & \\
\hline \multirow[t]{2}{*}{ SPM } & Mean & 1.18 & 1.20 & 0.99 & \multirow[t]{2}{*}{0.495} & 1.33 & 1.01 & 1.27 & \multirow[t]{2}{*}{0.050} \\
\hline & SD & 1.05 & 1.01 & 1.12 & & 1.01 & 1.10 & 0.95 & \\
\hline \multirow[t]{2}{*}{ FM } & Mean & 2.21 & 2.18 & 2.12 & \multirow[t]{2}{*}{0.802} & 2.15 & 2.07 & 2.36 & \multirow[t]{2}{*}{$0.018^{x}$} \\
\hline & SD & 0.80 & 0.93 & 0.91 & & 0.85 & 0.92 & 0.81 & \\
\hline \multirow[t]{2}{*}{ SM } & Mean & 1.61 & 1.60 & 1.69 & \multirow[t]{2}{*}{0.874} & 1.29 & 1.69 & 1.73 & \multirow[t]{2}{*}{0.084} \\
\hline & SD & 0.88 & 1.00 & 1.08 & & 1.01 & 1.00 & 0.83 & \\
\hline
\end{tabular}

When analyzed with a general linear regression model (Table $5 a$ and Table $5 b$ ), age was taken as continuous variables, and patient score, FPM score, SPM score, FM score, SM score as dependent variables. After controlling for age, significant differences were found between the ANB angle groups as well as the FMA angle groups for patient score, SPM score, FM score, and SM score. Age was associated with patient score and in some of the tooth scores, such as SPM score, FM score, and SM score, when considering the skeletal facial pattern. 
Table 5

a: Influence of the ANB angles on patient score and tooth score analyzed with general linear regression model (age as continuous variables)

\begin{tabular}{|c|c|c|c|c|c|}
\hline Dependent variable & Independent variable & Adjusted coefficient b & $95 \% \mathrm{Cl}$ for $\mathrm{b}$ & $P$ & $\mathrm{R}^{2}$ \\
\hline \multirow[t]{3}{*}{ Patient score } & constant & & $0.291-1.341$ & 0.002 & \multirow[t]{3}{*}{0.250} \\
\hline & Age & 0.176 & $0.015-0.075$ & 0.004 & \\
\hline & ANB & 0.043 & $-0.079-0.169$ & 0.476 & \\
\hline \multirow[t]{3}{*}{ FPM } & constant & & $-0.479-0.349$ & 0.758 & \multirow[t]{3}{*}{0.016} \\
\hline & Age & 0.148 & $0.006-0.053$ & 0.016 & \\
\hline & ANB & -0.036 & $-0.126-0.068$ & 0.552 & \\
\hline \multirow[t]{3}{*}{ SPM } & constant & & $-0.948-0.657$ & 0.721 & \multirow[t]{3}{*}{0.038} \\
\hline & Age & 0.207 & $0.032-0.124$ & 0.001 & \\
\hline & ANB & 0.051 & -0.1080 .263 & 0.410 & \\
\hline \multirow[t]{3}{*}{ FM } & constant & & $1.183-2.488$ & 0.000 & \multirow[t]{3}{*}{-0.002} \\
\hline & Age & 0.073 & $-0.015-0.060$ & 0.230 & \\
\hline & ANB & 0.009 & $-0.144-0.167$ & 0.885 & \\
\hline \multirow[t]{3}{*}{ SM } & constant & & $-0.871-1.189$ & 0.761 & \multirow[t]{3}{*}{0.051} \\
\hline & Age & 0.249 & $0.038-0.148$ & 0.001 & \\
\hline & ANB & 0.001 & $-0.202-0.205$ & 0.987 & \\
\hline
\end{tabular}

Table 5

b: Influence of the FMA angles on patient score and tooth score analyzed with general linear regression model (age as continuous variables)

\begin{tabular}{|c|c|c|c|c|c|}
\hline Dependent variable & Independent variable & Adjusted coefficient b & $95 \% \mathrm{Cl}$ for $\mathrm{b}$ & $P$ & $\mathrm{R}^{2}$ \\
\hline \multirow[t]{3}{*}{ Patient score } & constant & & $0.219-1.238$ & 0.005 & \multirow[t]{3}{*}{0.031} \\
\hline & Age & 0.180 & $0.016-0.076$ & 0.003 & \\
\hline & FMA & 0.086 & $-0.031-0.197$ & 0.151 & \\
\hline \multirow[t]{3}{*}{ FPM } & constant & & $-0.467-0.325$ & 0.725 & \multirow[t]{3}{*}{0.016} \\
\hline & Age & 0.147 & $0.005-0.053$ & 0.016 & \\
\hline & FMA & -0.039 & $-0.118-0.060$ & 0.522 & \\
\hline \multirow[t]{3}{*}{ SPM } & constant & & $-0.759-0.798$ & 0.961 & \multirow[t]{3}{*}{0.035} \\
\hline & Age & 0.207 & $0.032-0.124$ & 0.001 & \\
\hline & FMA & 0.005 & $-0.167-0.181$ & 0.941 & \\
\hline \multirow[t]{3}{*}{ FM } & constant & & $0.934-2.192$ & 0.000 & \multirow[t]{3}{*}{0.010} \\
\hline & Age & 0.078 & $-0.013-0.061$ & 0.201 & \\
\hline & FMA & 0.111 & $-0.010-0.272$ & 0.068 & \\
\hline \multirow[t]{3}{*}{ SM } & constant & & $-1.313-0.599$ & 0.462 & \multirow[t]{3}{*}{0.080} \\
\hline & Age & 0.259 & $0.043-0.150$ & 0.000 & \\
\hline & FMA & 0.169 & $0.033-0.405$ & 0.021 & \\
\hline
\end{tabular}

Correlations between patient score, tooth score, age, and facial skeletal malocclusions showed that patient score (Spearman's rho $[\rho]=$ 0.146; $P=0.004$, two tail), FPM score (Spearman's rho $[\rho]=0.133 ; P=0.015$, two tail), SPM score (Spearman's rho $[\rho]=0.164 ; P=0.001$, two 
tail), and SM score (Spearman's rho $[\rho]=0.195 ; P=0.001$, two tail) were significantly and positively correlated with age. Interestingly, FM score was not related to age without considering facial skeletal discrepancy. SM score was correlated with FMA angles (Spearman's rho $[\rho]=0.155 ; P=0.041$, two-tail test), indicating that more root apexes of the upper second molars were likely to penetrate into the sinus in the high-angle group. There was no significant correlation between sex and either tooth score or patient score (data not shown).

\section{Discussion}

There is a correlation between the root tips of upper posterior teeth and the extension of the MS floor in the skeletal malocclusion groups in adolescents. FMA angles seemed to be related to the root-sinus position. The proximity of the upper second molars roots to the sinus floor was positively related to the FMA angles, indicating that vertical facial skeletal malocclusion might influence the root-sinus relationship in the posterior maxillary area. We found that ANB angles were less related to root-sinus relationships, which suggests that in adolescents, the proximity of the posterior maxillary teeth to the sinus floor might be independent of the anteroposterior position of maxilla and mandible.

The root-sinus relationship has been studied in different age groups $7,8,14-19$. Ok et al reported that the relationship between the sinus floor and the posterior maxillary teeth differed with age. The results showed that the roots of the maxillary first and second molars drifted apart from the sinus floor with the increasing of age, especially in the fourth decade. Tian ${ }^{19}$ et al. confirmed that the proximity between the posterior maxillary teeth and the MS varied with age. And age less than 40 years showed a higher likelihood of roots above or inside the sinus floor. Park ${ }^{20}$ noted a significantly closer distance between maxillary root tips and the sinus floor with a high-angle skeletal pattern and a sizeable gonial angle in older (20-28 years) male groups than younger (10-20 years) female groups. These results were partly consistent with our study. We found that age (10-19 years) was significantly and positively related to the root-sinus position. Maxillary molar roots were more close the sinus floor with the increasing of age, however, no significant sex difference was found. We also demonstrated that there was a positive relationship between roots projecting into the sinus and the high-angle skeletal malocclusion. This finding was similar to the results of Costea ${ }^{21}$ et al., who showed that the roots of the second molars were located farther from the sinus floor in a hypodivergent biotype compared with the normodivergent and hyperdivergent facial patterns. A comparison of our findings with previous studies is difficult since most previous studies did not consider root-sinus types within skeletal malocclusion in adolescents.

Facial skeletal biotype is related to the growth of the mandible. Researches ${ }^{22}$ have shown relationships between facial skeletal characteristics and multiple factors like occlusal forces, morphology of masticatory muscles and shape of mandible. Due to short mandibular ramus in high-angle patients, the maxillary plane will rotate and a compensatory dentoalveolar mechanism will be induced ${ }^{23}$. Moreover, there seemed to be thinner cortical bone plates in hyperdivergent patients compared with normodivergent and hyperdivergent patients ${ }^{24,25}$. Thus, the sinus will expand because of weak cortical bone block, and roots of maxillary posterior teeth are more likely project into the sinus because of the absence of posterior dentoalveolar compensation. This may be to some extent explain why more molar roots would contact or inside the sinus in patients with high-angle skeletal malocclusion.

Factors including facial pattern, teeth crowding, and molar relationship, are involved in orthodontic treatment plans. The relationship between the MS floor extension and malocclusion also affects the orthodontic plan such as the intrusion of the maxillary posterior teeth. We showed that more than one-third of maxillary root tips in both Class II and the high-angle skeletal group (Table 2) intruded inside the sinus (type 3). This means that these intruded roots were surrounded by the cortical bone of the sinus floor. Moving teeth with sufficient bony support are crucial and can be accomplished with fewer side effects in orthodontic treatment. However, moving teeth in the cortical bone, like the MS, is challenging. Though several case reports ${ }^{26-28}$ and experimental studies ${ }^{29-31}$ demonstrated that teeth can be safely moved through the MS with continuous light force and appropriate orthodontic appliances, care should be taken when devising a treatment plan for adolescent patients with Class II discrepancy and the long faces, especially for those with hard orthodontic tooth movement (bodily movement or intrusion) through the sinus.

The MS floor comprises the maxillary alveolar process and the hard palate. The extension of the MS floor varies with age ${ }^{32}$, as it reaches the lowest point with the eruption of the third molars ${ }^{33,34}$. In adults, the MS floor extends between adjacent teeth, creating elevations in the antral surface ${ }^{33,35}$. The size of the MS differences in the age ${ }^{32,36}$ and gender ${ }^{1}$ of the individual. With increasing age, the sinus floor tends to resorb and then creates dehiscence around the tooth roots ${ }^{37-39}$. At 21-30 years of age, the MS is entirely developed ${ }^{32}$. The root apex relates to the sinus floor when they are in contact. Since Oktay ${ }^{6}$ and $\operatorname{Tian}^{19}$ et al established that the posterior teeth roots are more likely to contact or penetrate the sinus in people less than 40 years old. It is reasonable to believe that in 10- to 19-year-olds, the roots of the posterior maxillary teeth are more closely related to the sinus floor than in populations $>40$ years old. This close association may provide precautions for clinicians at the beginning of dealing with adolescent orthodontic patients. 
As a 2-dimensional (2D) radiographic imaging technique, panoramic radiography can be used to roughly assess the relationship between the MS floor and the posterior root apex. However, the reliability is uncertain due to the superposition and magnification of the anatomical structure $^{40}$. Compared with traditional panoramic radiographs, СВCT images can provide additional information and reduce error, making it useful for orthodontic diagnosis. For specific clinical scenarios, such as unerupted teeth, root resorption, and airway problems, the additional information provided by $\mathrm{CBCT}$ can result in a more clinically orientated treatment compared to conventional imaging ${ }^{41-45}$. In our study, 2D cephalometric radiographs were used to measure the ANB angle and the FMA angle. CBCT was used to assess the relationship between the posterior maxillary roots and the sinus floor at different orientations using Dolphin software. CBCT imaging provides unique features and advantages over conventional extra-oral radiographic imaging such as 3D visualization and virtual 3D model reconstruction ${ }^{46}$. In addition to these advantages, CBCT data can also be used for 3D cephalometric analysis. Obtaining ANB angles and FMA angles through 3D cephalometry is more precise and efficient. However, the large field of view (FOV), which covers most of the craniofacial skeleton, is recommended for 3D cephalometric analysis. Notably, when using CBCT imaging in orthodontics, examinations should not be routinely applied but should only be used on a case-by-case basis ${ }^{47}$ after considering the specific clinical situation and the needs of the patient.

\section{Conclusion}

The relationship between the maxillary posterior roots and the sinus floor is correlated with facial skeletal malocclusion in 10- to 19-yearold adolescents. We identified more first molar root tips inside the sinus in the high-angle group compared to the average-angle and lowangle groups. In the high-angle malocclusion, more second molar root tips contacted the sinus floor as the patient's age increased. Consideration of the root-sinus position of the posterior maxillary area in different skeletal malocclusion before establishing an orthodontic treatment plan is recommended.

\section{Abbreviations}

2D: 2-dimensional; 3D: three-dimensional; ANB angle: the angle between the NA (Nasion-A point) line and NB (Nasion-A point) line; CBCT: cone-beam computed tomography; FM: first molar; FMA: Frankfort mandibular plane angle; FPM: first premolar; MS: maxillary sinus; SM: second molar; SPM: second premolar; WHO: World Health Organization.

\section{Declarations}

\section{Ethics approval and consent to participate}

This study was approved by the Biomedical Ethics Committee of Anhui Medical University (No.20170091).

\section{Consent for publication}

Not applicable.

\section{Availability of data and materials}

The datasets used and/or analyzed in this study are available from the corresponding author on reasonable request.

\section{Competing interests}

There is no financial or non-financial competing interests.

\section{Funding}

This study was supported by Natural Science Foundation of Anhui Province (No.1908085MH255). The funding body fully refrained from exerting influence on any aspect of the study, neither regarding the design nor the data collection nor processing. 


\section{Authors' contributions}

JX developed the concept and design of this study. ZZ, XG collected the study samples. MX, XZ and YS performed the clinical examination. $W X$ contributed to the analysis of raw data. $\mathrm{JH}$ and $Y W$ supervised the data assessment. $W X$ and $M X$ performed statistical analyses, and all authors ( $M X, X Z, J H, X G, Y S, Z Z, Y W, W X$ and $J X)$ contributed to the interpretation of the data. Xu M drafted the manuscript. All authors ( $M X, X Z, J H, X G, Y S, Z Z, Y W, W X$ and JX) read and approved the final manuscript.

\section{Acknowledgements}

The authors would like to thank the participants from Jinan Stomatological Hospital for their contributions to this project.

\section{References}

1. Development of the maxillary. sinus from birth to age 18. Postnatal growth pattern. International Journal of Pediatric Otorhinolaryngology 79, 1393-1400.

2. Agnieszka P, et al The Association between Maxillary Sinus Dimensions and Midface Parameters during Human Postnatal Growth. Biomed Research International 2018, 1-10.

3. Wehrbein $\mathrm{H}$, Diedrich P. [The initial morphological state in the basally pneumatized maxillary sinus-a radiological-histological study in man]. Fortschr Kieferorthop. 1992;53:254-62.

4. The age of adolescence

Sawyer SM, Azzopardi PS, Wickremarathne D, Patton GC. The age of adolescence. (2018).

5. van den Bergh JP, ten Bruggenkate CM, Disch FJ, Tuinzing DB. Anatomical aspects of sinus floor elevations. Clin Oral Implants Res. 2000;11:256-65.

6. Oktay $\mathrm{H}$. The study of the maxillary sinus areas in different orthodontic malocclusions. Am J Orthod Dentofacial Orthop. 1992;102:143-5.

7. Ok E, Güngör E, Colak M, Altunsoy M, Ağlarci OS. Evaluation of the relationship between the maxillary posterior teeth and the sinus floor using cone-beam computed tomography. Surg Radiol Anat. 2014;36:907-14.

8. Kilic C, Kamburoglu K, Yuksel SP, Ozen T. An Assessment of the Relationship between the Maxillary Sinus Floor and the Maxillary Posterior Teeth Root Tips Using Dental Cone-beam Computerized Tomography. Eur J Dent. 2010;4:462-7.

9. Nino-Barrera JL, Ardila E, Guaman-Pacheco F, Gamboa-Martinez L, Alzate-Mendoza D. Assessment of the relationship between the maxillary sinus floor and the upper posterior root tips: Clinical considerations. Journal of Investigative Clinical Dentistry. 2017;9:e12307.

10. Ludlow JB, Walker C. Assessment of phantom dosimetry and image quality of i-CAT FLX cone-beam computed tomography. American Journal of Orthodontics Dentofacial Orthopedics. 2013;144:802-17.

11. EH A. Treatment of malocclusion of the teeth: Angle's system. Philadelphia: S. S. White Dental Manufacturing Company (1907).

12. Steiner CC. Cephalometrics for you and me. Am J Orthod. 1953;39:729-55.

13. CH T. The FrankfortMandibular Incisor Angle (FMIA) In Orthodontic Diagnosis. Treatment Planning Prognosis Angle Orthod. 1954;24:121-169.

14. Jung $\mathrm{YH}, \mathrm{Cho} \mathrm{BH}$. Assessment of the relationship between the maxillary molars and adjacent structures using cone beam computed tomography. Imaging Sci Dent. 2012;42:219-24.

15. Kwak HH, et al. Topographic anatomy of the inferior wall of the maxillary sinus in Koreans. Int J Oral Maxillofac Surg. 2004;33:382-8.

16. Howe RB. First molar radicular bone near the maxillary sinus: a comparison of CBCT analysis and gross anatomic dissection for small bony measurement. Oral Surg Oral Med Oral Pathol Oral Radiol Endod. 2009;108:264-9.

17. Kim TS, Caruso JM, Christensen H, Torabinejad M. A comparison of cone-beam computed tomography and direct measurement in the examination of the mandibular canal and adjacent structures. J Endod. 2010;36:1191-4.

18. Ariji Y, et al. Roots of the maxillary first and second molars in horizontal relation to alveolar cortical plates and maxillary sinus: computed tomography assessment for infection spread. Clin Oral Investig. 2006;10:35-41.

19. Tian XM, Qian L, Xin XZ, Wei B, Gong Y. An Analysis of the Proximity of Maxillary Posterior Teeth to the Maxillary Sinus Using Conebeam Computed Tomography. Journal of Endodontics. 2016;42:371-7. 
20. Ahn NL, Park HS. Differences in distances between maxillary posterior root apices and the sinus floor according to skeletal pattern. American journal of orthodontics dentofacial orthopedics: official publication of the American Association of Orthodontists its constituent societies the American Board of Orthodontics. 2017;152:811.

21. Costea MC, et al. Proximity of the roots of posterior teeth to the maxillary sinus in different facial biotypes. Am J Orthod Dentofacial Orthop. 2018;154:346-55.

22. Szymanska J, Sidorowicz L. The relationship between selected parameters of a cephalometric analysis determining the vertical morphology of facial skeleton and bite force. Folia Morphol (Warsz) (2017).

23. Sadek MM, Sabet NE, Hassan IT. Alveolar bone mapping in subjects with different vertical facial dimensions. Eur J Orthod. 2015;37:194-201.

24. Ozdemir F, Tozlu M, Germec-Cakan D. Cortical bone thickness of the alveolar process measured with cone-beam computed tomography in patients with different facial types. Am J Orthod Dentofacial Orthop. 2013;143:190-6.

25. Lo Giudice A, Rustico L, Caprioglio A, Migliorati M, Nucera R. Evaluation of condylar cortical bone thickness in patient groups with different vertical facial dimensions using cone-beam computed tomography. Odontology (2020).

26. Re S, Cardaropoli D, Corrente G, Abundo R. Bodily tooth movement through the maxillary sinus with implant anchorage for single tooth replacement. Clin Orthod Res. 2010;4:177-81.

27. Renato SDC, Alberto C, Carlos Eduardo F. Sinus augmentation by orthodontic movement as an alternative to a surgical sinus lift: a clinical report. J Prosthet Dent. 2014;112:723-6.

28. Oh H, et al. Orthodontic tooth movement through the maxillary sinus in an adult with multiple missing teeth. Orthod Fr. 2015;146:31326.

29. Daimaruya T, et al. Effects of maxillary molar intrusion on the nasal floor and tooth root using the skeletal anchorage system in dogs. Angle Orthod. 2003;73:158-66.

30. Kuroda S, Wazen R, Moffatt P, Tanaka E, Nanci A. Mechanical stress induces bone formation in the maxillary sinus in a short-term mouse model. Clin Oral Investig. 2013;17:131-7.

31. Maeda Y, et al. Histomorphometric analysis of overloading on palatal tooth movement into the maxillary sinus. Am $\mathrm{J}$ Orthod Dentofacial Orthop. 2015;148:423-30.

32. Jun BC, et al. The analysis of maxillary sinus aeration according to aging process; volume assessment by 3-dimensional reconstruction by high-resolutional CT scanning. Otolaryngol Head Neck Surg. 2005;132:429-34.

33. Sharan A, Madjar D. Maxillary sinus pneumatization following extractions: a radiographic study. Int J Oral Maxillofac Implants. 2008;23:48-56.

34. AF., L. Surgical and Radiologic Anatomy for Oral Implantology,1st ed. Hanover, Germany: Quintessence Publishing(2013).

35. Park JH, Tai K, Kanao A, Takagi M. Space closure in the maxillary posterior area through the maxillary sinus. Am J Orthod Dentofacial Orthop. 2014;145:95-102.

36. Barghouth G, et al. Paranasal sinuses in children: size evaluation of maxillary, sphenoid, and frontal sinuses by magnetic resonance imaging and proposal of volume index percentile curves. Eur Radiol. 2002;12:1451-8.

37. Bell GW, Joshi BB, Macleod RI. Maxillary sinus disease: diagnosis and treatment. Br Dent J. 2011;210:113-8.

38. Lee JE, Jin SH, Ko Y, Park JB. Evaluation of anatomical considerations in the posterior maxillae for sinus augmentation. World J Clin Cases. 2014;2:683-8.

39. Woo I, Le BT. Maxillary sinus floor elevation: review of anatomy and two techniques. Implant Dent. 2004;13:28-32.

40. Sharan A, Madjar D. Correlation between maxillary sinus floor topography and related root position of posterior teeth using panoramic and cross-sectional computed tomography imaging. Oral Surg Oral Med Oral Pathol Oral Radiol Endod. 2006;102:375-81.

41. Alqerban A, et al. Orthodontic treatment planning for impacted maxillary canines using conventional records versus 3D CBCT. Eur $\mathrm{J}$ Orthod. 2014;36:698-707.

42. Haney $\mathrm{E}$, et al. Comparative analysis of traditional radiographs and cone-beam computed tomography volumetric images in the diagnosis and treatment planning of maxillary impacted canines. Am J Orthod Dentofacial Orthop. 2010;137:590-7.

43. Botticelli S, Verna C, Cattaneo PM, Heidmann J, Melsen B. Two- versus three-dimensional imaging in subjects with unerupted maxillary canines. Eur J Orthod. 2011;33:344-9.

44. Hodges RJ, Atchison KA, White SC. Impact of cone-beam computed tomography on orthodontic diagnosis and treatment planning. Am J Orthod Dentofacial Orthop. 2013;143:665-74. 
45. Alqerban A, et al. Pre-surgical treatment planning of maxillary canine impactions using panoramic vs cone beam CT imaging. Dentomaxillofac Radiol. 2013;42:20130157.

46. Scarfe WC, Azevedo B, Toghyani S, Farman AG. Cone Beam Computed Tomographic imaging in orthodontics. Aust Dent J. 2017;62(Suppl 1):33.

47. Kirkham-Ali K, La M, Sher J, Sholapurkar A. Comparison of cone-beam computed tomography and panoramic imaging in assessing the relationship between posterior maxillary tooth roots and the maxillary sinus: A systematic review. J Investig Clin Dent. 2019;10:e12402.

\section{Figures}

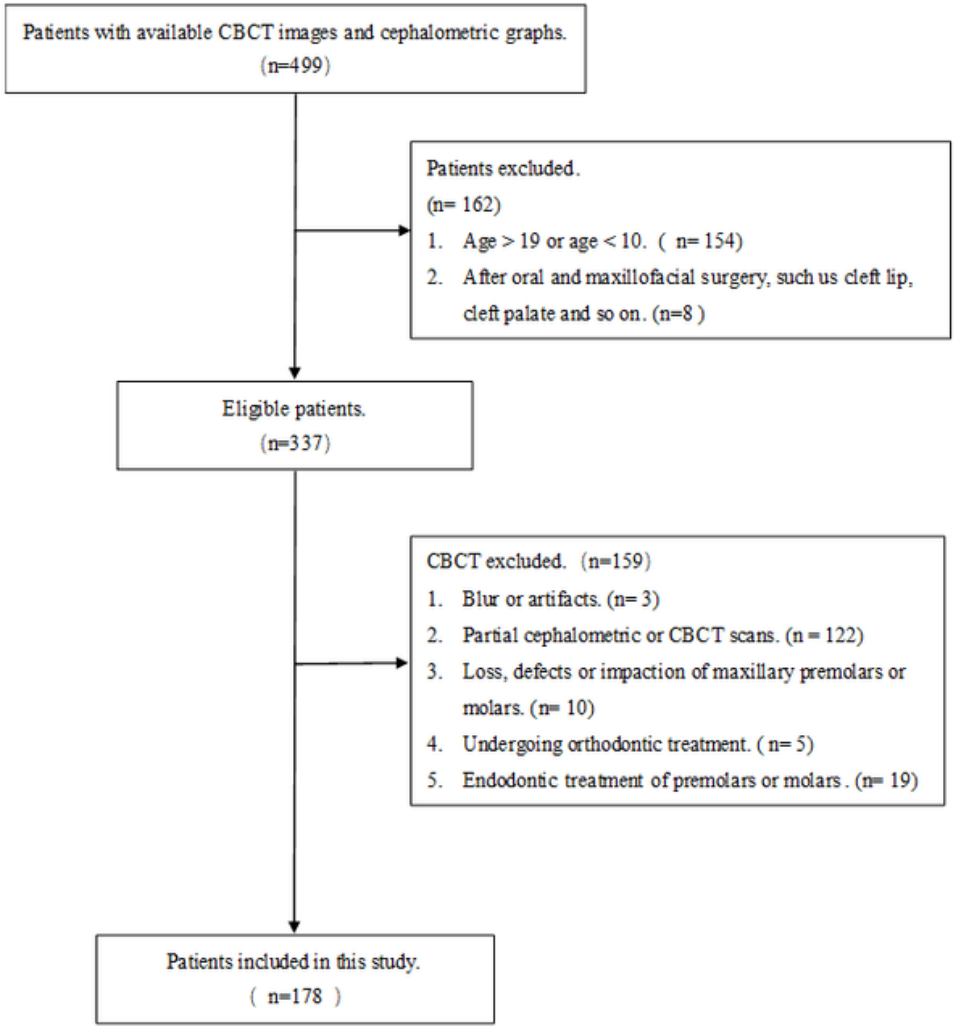

\section{Figure 1}

Flow chart of excluded and included patients
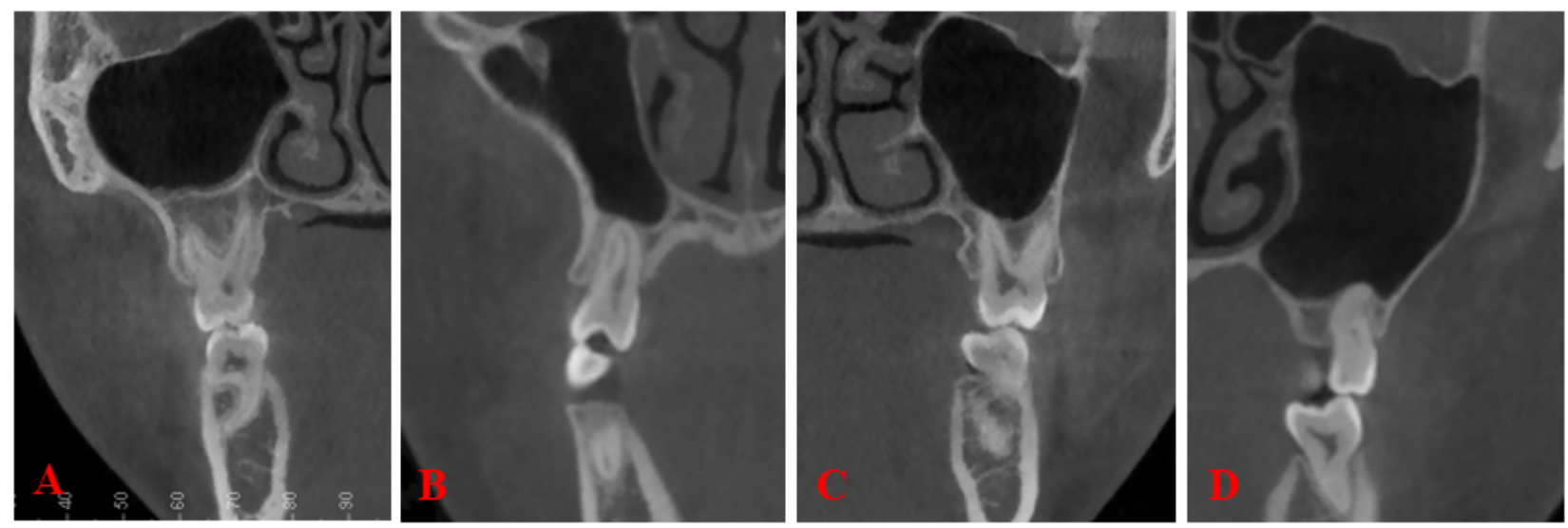


\section{Figure 2}

CBCT images show the vertical spatiality between the maxillary sinus floor and molar root apex: A.0, no contact between the root and the cortical borders of the maxillary sinus; B.1, slight contact between the root and the cortical borders of the maxillary sinus; C.2, the lateral protrusion of a root in the sinus cavity without the projection of its apex into the sinus; D.3, the projection of the root apex into the sinus cavity. 